\title{
IgM anti-SARS-CoV-2-specific determination: useful or confusing? Big Data analysis of a real-life scenario
}

\author{
Tommaso Trenti ${ }^{1} \cdot$ Valentina Pecoraro $^{1}$ (i) $\cdot$ Tommaso Pirotti $^{1} \cdot$ Mario Plebani $^{2}$
}

Received: 31 January 2021 / Accepted: 15 April 2021 / Published online: 2 May 2021

c) Società Italiana di Medicina Interna (SIMI) 2021

Keywords SARS-CoV-2 - COVID-19 · Accuracy $\cdot$ IgG to SARS-CoV-2 $\cdot$ IgM to SARS-CoV-2

Dear Editor,

Current studies have highlighted the rapid transmissibility of the SARS-CoV-2 virus, causing the COVID-19 pandemic, also among asymptomatic or minimally symptomatic subjects. The clinical pathway for COVID-19 diagnosis has been traced throughout the world and laboratory workflows have been defined with validated detection methods, including accurate molecular and antigenic laboratory tests. The detection of SARS-CoV-2 RNA in nasopharyngeal and/ or oropharyngeal swabs has rapidly developed and made available for the identification of patients affected by SARSCoV-2 infection, with adequate sensitivity and specificity [1]. Concurrently, serological tests identifying SARS-CoV2 -specific antibodies (Abs), especially $\operatorname{IgG}$ and $\operatorname{IgM}$, in serum were made available and have been herald as essential for SARS-CoV-2 viral infection surveillance within the community to assist in both economic and social recovery. However, the immunological significance of IgG and IgM are currently undefined, including the duration of protection against SARS-CoV-2 viral infection and what they signify in asymptomatic subjects. Further, the utility of $\operatorname{IgG}$ and $\operatorname{IgM}$ in acute infection diagnosis is limited by several factors,

Valentina Pecoraro

v.pecoraro@ausl.mo.it

Tommaso Trenti

t.trenti@ausl.mo.it

Tommaso Pirotti

t.pirotti@ausl.mo.it

Mario Plebani

mario.plebani@unipd.it

1 Department of Laboratory Medicine and Pathology, Azienda USL of Modena, Modena, Italy

2 Department of Laboratory Medicine, University-Hospital of Padova, Padova, Italy such as symptom onset and cross-reactivity to non-SARSCoV-2 virus proteins. Negative serological results do not exclude SARS-CoV-2 infection, especially among subjects with recent exposure to the SARS-CoV-2 virus.

Serologic assays for SARS-CoV-2 play an important role in understanding the viral epidemiology in the general population, by determining the proportion of a population with previous SARS-CoV-2 infection, and identifying groups at higher risk for infection or groups potentially immune (https://www.cdc.gov/coronavirus/2019-ncov/lab/resources/ antibody-tests-guidelines.html). Available evidence showed that serological test are characterized by low sensibility and high specificity, and could provide a rapid answer for suspected case of COVID-19. However, in low prevalence settings, these tests may provide false-positive results, resulting in a low positive predictive value [2].

Current epidemiological studies suggest that in SARSCoV-2 infections, IgM and IgG may arise almost simultaneously within 2-3 weeks after illness onset, but how long these specific antibodies remain detectable following infection is subject of study for several researchers [3] or, in some subjects, be undetectable following infection. Thus, the identification of $\operatorname{IgG}$ and IgM may be clinically insignificance unless associated with other laboratory or imaging test results.

Currently, there are many methods available for the detection of specific Abs, including enzyme-linked immunosorbent assay (ELISA), chemiluminescent assay (CLIA), or Lateral Flow Immunochromatographic Assays (LFIA), which all have relatively high throughput capacity and less stringent specimen requirements compared to RNA-based assays. However, diagnostic accuracy remains suboptimal [4], and Abs testing alone is unlikely to be adequate in assisting clinical decision. A recent meta-analysis reported a wide range of pooled sensitivity among different assay methods (97.8\% for CLIA and $66 \%$ for LFIA) yet consistent rates if adequate 
specificities (96.6\% vs 99.7\%) [5]. Furthermore, specific IgG and IgM accuracy are different. IgG serology has high sensitivity and specificity that improves when performed more than 2 weeks after RNA detection, confirming the clinical significance of $\operatorname{IgG}$ for epidemiologic studies. IgM is usually interpreted as an indicator of acute infection but due to low sensibility, rates of false-negative results questions its usefulness in limiting the spread of SARS-CoV-2 infection $[6,7]$, even if its role in neutralization activity has been demonstrated $[8,9]$.

We, therefore, aimed to assess the clinical utility of IgM detection in SARS-CoV-2 infection based on a clinical reality. We conducted a retrospective study with big data analysis of a laboratory database, including all serological tests for specific SARS-CoV-2 Abs IgG and IgM detection and oropharyngeal and nasopharyngeal swabs for SARSCoV-2 RNA detection (Alinity m SARS-CoV-2 AssayAbbott Molecular), executed between 11 March 2020 and 30 September 2020, in an Italian province of 700.000 people (www.modenastatistiche.it). During the study period, a total of 69,343 serological tests (in 42,911 subjects) and 140,065 swabs (in 88,771 subjects) were performed at laboratory of the public hospital of Modena (Table 1). All serum samples

Table 1 Serological tests and RNA viral detection with relative positivity observed during the study period

\begin{tabular}{lll}
\hline & $\begin{array}{l}\text { Number of } \\
\text { tests performed }\end{array}$ & Number of subjects (\%) \\
\hline $\begin{array}{l}\text { Serological test for specific } \\
\text { SARS-CoV-2 Abs IgG }\end{array}$ & 69,343 & 42,911 \\
$\begin{array}{l}\text { and IgM detection } \\
\text { IgM positive results }\end{array}$ & $1235(1.8 \%)$ & $904(2.1 \%)$ \\
$\begin{array}{l}\text { IgG positive results } \\
\text { Oropharyngeal and } \\
\text { nasopharyngeal swabs } \\
\text { for SARS-CoV-2 RNA } \\
\text { detection }\end{array}$ & $14524(5.1 \%)$ & $2132(5.0 \%)$ \\
Positive results & $8278(5.9 \%)$ & 4796,771 \\
\hline
\end{tabular}

collected from health care workers were processed using qualitative and commercially available, rapid lateral flow immunoassay tests (Techno Genetics KHB Group-Shanghai) for 2019-nCoV IgG and IgM antibodies. Positive results to either $\operatorname{IgG}$ or IgM or both $\operatorname{IgG}$ and IgM were confirmed using a chemiluminescent method (iFlash 1800-YHLO Biotech Co., Ltd., Shenzhen, China). All the tests were $\mathrm{CE}$ compliant and were performed according to manufacturers' instructions with maximum standardization (room temperature, sample volume, reading time, etc.). Subjects with a positive result were contacted from the Department of Public Health for further tests (viral RNA research or subsequent serological tests) for definitive diagnosis (Fig. 1). The median time between first serological test and subsequent molecular test was 7 days. Most subjects screened $(n=40,559 ; 94.5 \%)$ had negative results for both $\mathrm{IgG}$ and IgM. Of the 640 subjects (1.5\%) with IgG and IgM positive results, 533 oro- or nasopharyngeal swabs were performed and viral RNA research confirmed positivity in $16 \%(n=85)$. Of the subjects with $\operatorname{IgG}$ negative and $\operatorname{IgM}$ positive/dubious results with subsequent swabs, viral RNA research confirmed positivity in only $1.4 \%(n=7 / 478)$ subjects. Subsequent serological testing showed that 187 subjects were IgG-/IgM-, and confirmed IgG positivity in 8 subjects (1.6\%). Of these, only 1 patient had a previous IgM positive result, instead 3/7 patients with a first IgM positive result had subsequent $\mathrm{IgG}$ seroconversion. However, of subjects with IgM positive/dubious 638 (49\%) performed a subsequent serological test in median 17 days after the first, and 406/638 (63\%) had IgM- result. Conversely, in subjects with IgG positive and IgM negative/dubious, a positivity rate of $7.8 \%$ was confirmed (104/1335 swabs performed). Therefore, analysis suggests that up to $98 \%$ of serological test results of $\operatorname{IgM}$ positivity/dubious and $\mathrm{IgG}$ negativity are false positive whereas, serological test results of IgG positive and IgM negative/dubious are confirmed true positives in around $7.9 \%$ of subjects. Therefore, although IgM positive/dubious and $\operatorname{IgG}$ negative is uncommon (1.2\%), results

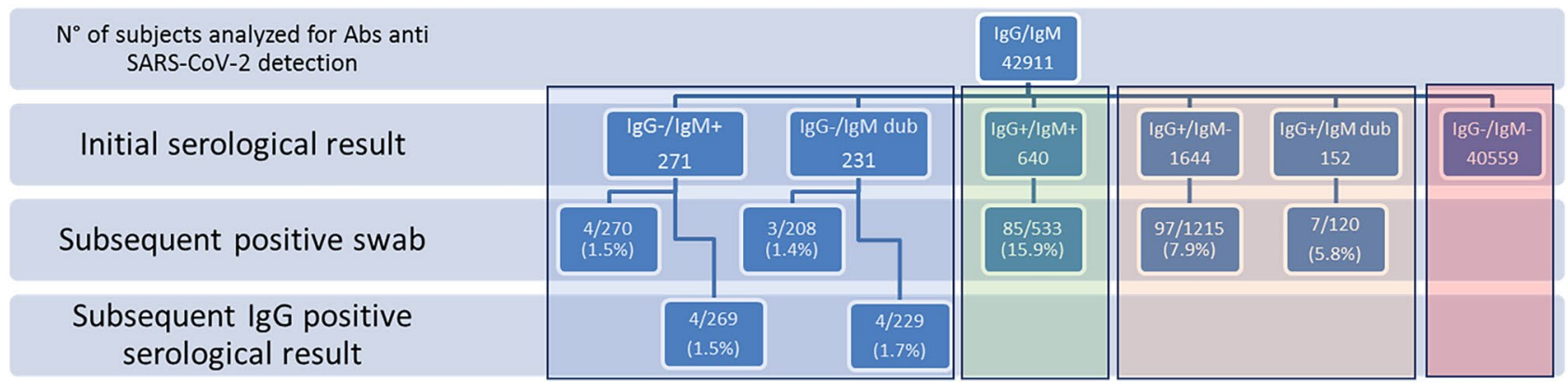

Fig. 1 Testing pathway: serological test and RNA viral detection with relative positivity according to initial IgG and IgM observations. Dub dubious 
do not appear to be useful in the identification of patients infected with SARS-CoV-2.

Currently serological tests are incorporated in European and International guidelines for testing symptomatic and asymptomatic patients, as well as contacts of positive cases. To improve serological testing performance, an algorithm considering the combination of two or more tests has been hypothesized to increase positive predictive value from 50 to $100 \%$ (https://www.fda.gov/medical-devices/coronavirusdisease-2019-covid-19-emergency-use-authorizations-medic al-devices/eua-authorized-serology-test-performance) and may be more useful to guide COVID-19 diagnosis and management, as well as assess the epidemiology of the infection.

Furthermore, antibodies against the receptor-binding domain of the spike protein and the nucleocapsid protein are now detectable and have been associated with neutralizing activity, but it is not certain that the their presence in serum protects against subsequent reinfection. Consequently, individuals who have had past SARS-CoV-2 infection could potentially be reinfected and then contribute to viral transmission, leading to a false sense of protective immunity [10].

Despite limitations, SARS-CoV-2 serological tests have several applications in public health; safeguarding patient, healthcare workers and general population health; assessing the chance of reinfection in subjects with $\operatorname{IgG}$ positive results; estimating the risk of transmission within a community. Moreover, the application of serological tests assist in community social life, enabling interventions such as getting back to school and work despite a global pandemic. Further assessment of serological test efficacy are needed to optimize COVID-19 detection methodology, therefore, providing important information about previous infection, and to clarify important questions, such as the clinical significance of the presence of antibodies and the degree and duration of immunity protection.

Overall, the serology tests can be used to establish the real extent of an outbreak, map its geographical distribution, and identify at high-risk subjects, but they are not appropriate for the population screening, especially in low prevalence settings where this approach may results in false-positive. However, asymptomatic patients or those at early stage of disease might have low antibody concentrations that could give false-negative results. At present, RT-PCR analysis on clinical specimens from patients with suspected COVID19 is considered the confirmatory test for the diagnosis of SARS-CoV-2 infection by WHO and Centers of Disease Control and Prevention (https://www.ecdc.europa.eu/en/ publications-data/novel-coronavirus-sars-cov-2-dischargecriteria-confirmed-covid-19-cases). Despite the good diagnostic accuracy, the efficiency of RT-PCR depends on many factors, including sample type, stage of infection, time from onset of symptoms, and need of high-specialized laboratory technicians $[11,12]$. In this condition, the antigen test, rapid, cheap and easy to perform test, is developed and introduced for screening at high-risk subjects. Although less sensitive than molecular tests in detecting viral RNA, antigen tests perform well on individuals with high viral load in their upper respiratory tract [13].

In summary, our study, based on big data analysis application, does not support the use of serological test for medical decision making, confirms the scarce clinical utility of IgM anti SARS-CoV-2 detection in COVID-19 management, and underlines the responsibility of laboratory medicine professionals to highlight limitations of the SARS-CoV-2 serological tests due to uncertainty in their interpretation.

Author contributions All the authors have accepted responsibility for the entire content of this submitted manuscript and approved submission. TT conceived and designed the study. VP and TP entered and analyzed the data. All the authors prepared the full review and contributed to its revision, interpretation of results, and approval.

Funding The authors received no financial support for the research, authorship, and/or publication of this article.

\section{Declarations}

Conflict of interest The authors declared no potential conflicts of interest with respect to the research, authorship, and/or publication of this article.

Statement of human and animal rights Not available.

Informed consent Not available.

\section{References}

1. Duarte ML, Santos LRD, Contenças ACS, Iared W, Peccin MS, Atallah ÁN (2020) Reverse-transcriptase polymerase chain reaction versus chest computed tomography for detecting early symptoms of COVID-19. A diagnostic accuracy systematic review and meta-analysis. Sao Paulo Med J 138:422-432

2. Peeling RW, Wedderburn CJ, Garcia PJ, Boeras D, Fongwen N, Nkengasong J et al (2020) Serology testing in the COVID-19 pandemic response. Lancet Infect Dis 20(9):e245-e249

3. Sethuraman N, Jeremiah SS, Ryo A (2020) Interpreting diagnostic tests for SARS-CoV-2. JAMA 323:2249-2251

4. Moura DTH, McCarty TR, Ribeiro IB, Funari MP, Oliveira PVAG, Miranda Neto AA et al (2020) Diagnostic characteristics of serological-based COVID-19 testing: a systematic review and meta-analysis. Clinics (Sao Paulo) 75:e2212

5. Lisboa Bastos M, Tavaziva G, Abidi SK, Campbell JR, Haraoui LP, Johnston JC et al (2020) Diagnostic accuracy of serological tests for COVID-19: systematic review and meta-analysis. BMJ 370:m2516

6. Lahner E, Dilaghi E, Prestigiacomo C, Alessio G, Marcellini L, Simmaco M et al (2020) Prevalence of Sars-Cov-2 infection in health workers (HWs) and diagnostic test performance: the experience of a teaching hospital in central Italy. Int J Environ Res Public Health 17(12):4417 
7. Deeks JJ, Dinnes J, Takwoingi Y, Davenport C, Spijker R, TaylorPhillips S et al (2020) Antibody tests for identification of current and past infection with SARS-CoV-2. Cochrane Database Syst Rev 6(6):CD03652

8. Padoan A, Bonfante F, Pagliari M, Bortolami A, Negrini D, Zuin $S$ et al (2020) Analytical and clinical performances of five immunoassays for the detection of SARS-CoV-2 antibodies in comparison with neutralization activity. EBioMedicine 62:103101

9. Klingler J, Weiss S, Itri V, Liu X, Oguntuyo KY, Stevens C et al (2020) Role of IgM and IgA antibodies in the neutralization of SARS-CoV-2. J Infect Dis 24:jiaa784

10. Tillett RL, Sevinsky JR, Hartley PD, Kerwin H, Crawford N, Gorzalski A et al (2021) Genomic evidence for reinfection with SARS-CoV-2: a case study. Lancet Infect Dis 21(1):52-58

11. Zou LR, Ruan F, Huang MX et al (2020) SARS-CoV-2 viral load in upper respiratory specimens of infected patients. N Engl J Med 382(12):1177-1179
12. Zhao J, Yuan Q, Wang $\mathrm{H}$ et al (2020) Antibody responses to SARS-CoV-2 in patients of novel coronavirus disease 2019. Clin Infect Dis 71:ciaa344

13. Ciotti M, Maurici M, Pieri M, Andreoni M, Bernardini S (2021) Performance of a rapid antigen test in the diagnosis of SARSCoV-2 infection. J Med Virol. https://doi.org/10.1002/jmv.26830

Publisher's Note Springer Nature remains neutral with regard to jurisdictional claims in published maps and institutional affiliations. 